\title{
On-chip thermoelectric module comprised of oxide thin film legs
}

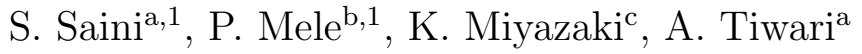 \\ ${ }^{a}$ Department of Materials Science and Engineering, University of Utah, Salt Lake City, \\ USA. \\ ${ }^{b}$ Research Center for Environmentally Friendly Materials Engineering, Muroran Institute \\ of Technology, Muroran, Japan. \\ ${ }^{c}$ Department of Mechanical Engineering, Kyushu Institute of Technology, Kitakyushu, \\ Japan.
}

\section{Abstract}

On-chip thermoelectric thin film modules containing 5 legs of $n$-type $\left(\mathrm{Al}_{0.02} \mathrm{Zn}_{0.98} \mathrm{O}\right)$ and 5 legs of $p$-type $\left(\mathrm{Ca}_{3} \mathrm{Co}_{4} \mathrm{O}_{9}\right)$ were fabricated on $\mathrm{Al}_{2} \mathrm{O}_{3}, \mathrm{SrTiO}_{3}$ single crystal, and fused silica substrates by pulsed laser deposition technique. Performance of modules was evaluated using ad-hoc customized system where the module was set vertically for temperature gradient. The maximum output power $\left(\mathrm{P}_{\max }\right)$ was obtained on $\mathrm{Al}_{2} \mathrm{O}_{3}(0001)$ single crystal substrate with temperature difference $(\Delta \mathrm{T})=230^{\circ} \mathrm{C}\left(\mathrm{T}_{h}=300^{\circ} \mathrm{C}\right): \mathrm{P}_{\max }=29.9 \mathrm{pW}$. The value of maximum output power increases with increase of temperature difference $(\Delta \mathrm{T})$. These results are encouraging for the practical applications of

\footnotetext{
Email addresses: ssaini@mse.utah.edu (S. Saini), pmele@mmm.muroran-it.ac.jp (P. Mele)

${ }^{1}$ Both authors contributed equally to this paper
} 
thermoelectric oxide thin films.

Keywords: Oxide Thin film, Thermoelectric, Pulsed Laser Deposition, On-chip Module, Thermoelectric Module

1 1. Introduction

2 In the recent years, oxide materials have increasingly gained attention in 3 the thermoelectric community due to their promising characteristics: high 4 stability at high temperatures $\left(600^{\circ} \mathrm{C}\right.$ and more), low price, non-toxicity. 5 Consequently, oxides have been started to be regarded as alternative to inter6 metallic and alloys for the fabrication of modules to convert waste heat into 7 electricity. Reviews on thermoelectric bulk oxides $[1,2,3,4,5,6]$ show 8 that the thermoelectric performance is still poor in comparison with metal9 lic materials and requires improvement. The performance of thermoelectric 10 materials is determined by the dimensionless figure of merit $\mathrm{ZT}=\sigma \cdot \mathrm{S}^{2} . \mathrm{T} / \kappa$

11 (S: Seebeck coefficient; $\sigma$ : electrical conductivity; $\kappa$ : thermal conductivity;

12 T: absolute temperature)[7].

13 Still the thermoelectric performance of the best $n$-type bulk oxide $\mathrm{Zn}_{0.96} \mathrm{Al}_{0.02} \mathrm{Ga}_{0.02} \mathrm{O}$

${ }_{14}(\mathrm{ZT}=0.65$ at $1273 \mathrm{~K})[8]$ and the best $p$-type $\mathrm{Ca}_{2.8} \mathrm{Lu}_{0.15} \mathrm{Ag}_{0.05} \mathrm{Co}_{4} \mathrm{O}_{9}(\mathrm{ZT}$

${ }_{15}=0.6$ at $\left.1100 \mathrm{~K}\right)[9]$ is lower than the benchmark ZT $=1$, which is commonly

reached by metallic materials (whose generally decompose or become unsta- 
ble at around $600^{\circ} \mathrm{C}$ ). Nevertheless, several contributions related to modules based on $\mathrm{ZnO}$ as $n$-type material and $\mathrm{Ca}_{3} \mathrm{Co}_{4} \mathrm{O}_{9}$ as $p$-type material have been published $[9,10,11]$. Depending on the number of legs and difference of temperature $(\Delta \mathrm{T})$, the typical output power $(\mathrm{P})$ of these modules is several milliwatts at high temperatures: $\mathrm{P}=3.7 \sim 423 \mathrm{~mW} ; \Delta \mathrm{T}=260 \sim 658 \mathrm{~K}$, $\mathrm{T}_{h}$ (temperature of hot-end of the module $)=773 \sim 1100 \mathrm{~K}$, as summarized in $[9]$.

These values are promising and there is a wide room for improvement related to the reduction of high internal resistance of the module and enhancement of the performance of the materials. As a paradigm for any kind of thermoelectric material $[12,13]$, the introduction of nano-sized defects leads to improved phonon scattering, consequently decreasing thermal conductivity and improving ZT [14, 15, 16, 17, 18]. This pattern has have been followed successfully in nano-structured BiTe/PbTe multilayers [19], AgPbSbTe alloys embedded with Ag-rich nano-inclusions [20], porous Al-doped $\mathrm{ZnO}$ [21], atomically substituted oxides with natural nano-sized precipitates $[8,9]$, nano-engineering $[22,23]$, and many more $[24,25]$. The main issue is to control the size and distribution of the nano-structures (nano-layers, pores, precipitates, secondary phases) inside the thermoelectric matrix, which have 
been found quite hard in bulk materials $[14,15,16,17]$. The control of nano-structure and defects in epitaxial thin films through strain engineering and artificial defects are at the advanced stage in several categories of functional oxides such as multiferroics [26], ferroics [27], superconductors [28], electronics [29], and more [30]. This approach is still at preliminary stage in thermoelectric oxide thin films [31].

Anyway, high thermoelectric performance has been reported by various groups in $p$-type $[32,33,34]$ and $n$-type $[35,36,37,38]$ nano-engineered oxide thin films, including our previous reports on Al-doped $\mathrm{ZnO}[39,40]$. The natural consequence is the use of thermoelectric thin films as legs for planar modules. However, to the date, very few reports on fabrication of thermoelectric oxide modules based on thin films have been published [41, 42, 43]. According to our best knowledge, only one evaluation of thin films module performance was reported: $\mathrm{P}=0.4 \mathrm{pW} / \mathrm{K}^{2}$ in a planar module based on $\mathrm{CuO}$ and $\mathrm{ZnO}$ legs obtained by sputtering on $\mathrm{Al}_{2} \mathrm{O}_{3}$ substrate [43].

The aim of this work is to make progress in exploring the field, describing planar modules based on $n$-type $\mathrm{ZnO}$ and $p$-type $\mathrm{Ca}_{3} \mathrm{Co}_{4} \mathrm{O}_{9}$ thin film legs fabricated by pulsed laser deposition (PLD) technique. The role of substrate is investigated by evaluating the performance of the module on $\mathrm{Al}_{2} \mathrm{O}_{3}, \mathrm{SrTiO}_{3}$ 
55

(STO) and fused silica.

\section{Experimental Technique}

The on-chip thermoelectric module was fabricated by pulsed laser deposition (PLD) technique using Nd:YAG laser (266 nm). Two pellets (20 mm in diameter and $3 \mathrm{~mm}$ in thickness) of $\mathrm{Zn}_{0.98} \mathrm{Al}_{0.02} \mathrm{O}(\mathrm{AZO})$ and $\mathrm{Ca}_{3} \mathrm{Co}_{4} \mathrm{O}_{9}$ were prepared by spark plasma sintering and used as the targets in PLD chamber for the thin films deposition.

At first, laser was focused on $\mathrm{Ca}_{3} \mathrm{Co}_{4} \mathrm{O}_{9}$ target and $p$-type legs were deposited on $10 \mathrm{~mm} \times 10 \mathrm{~mm}$ substrates by superimposing a custom nickel mask (Ni mask) (Micron Co. Ltd, Osaka) using the following conditions: energy density of about $1.1 \mathrm{~J} / \mathrm{cm}^{2}$; deposition period of $30 \mathrm{~min}$; deposition temperature $\left(\mathrm{T}_{d e p}\right)=700^{\circ} \mathrm{C}$ on $\mathrm{Al}_{2} \mathrm{O}_{3}$ and fused silica substrates, $\mathrm{T}_{d e p}=$ $650^{\circ} \mathrm{C}$ on STO substrates; oxygen pressure of 200 mTorr; laser pulse frequency $10 \mathrm{~Hz}$; substrate-target distance about $35 \mathrm{~mm}$; rotation speed of the target $30 \% \mathrm{rpm}$. Optimal deposition temperatures for $\mathrm{Ca}_{3} \mathrm{Co}_{4} \mathrm{O}_{9}$ thin films were chosen after screening from $550^{\circ} \mathrm{C}$ to $850^{\circ} \mathrm{C}$ : films not showing any X-ray diffraction (XRD) peak were discarded.

Then, Al-doped ZnO (AZO) target was moved under the laser beam and 
ablated to fabricate n-legs after shifting the custom Ni mask. Conditions used for AZO legs were same as for $\mathrm{Ca}_{3} \mathrm{Co}_{4} \mathrm{O}_{9}$ legs except for higher energy density (about $\left.4.2 \mathrm{~J} / \mathrm{cm}^{2}\right)$ and lower $\mathrm{T}_{\text {dep }}\left(400^{\circ} \mathrm{C}\right.$ on $\mathrm{Al}_{2} \mathrm{O}_{3}$ substrate, $300^{\circ} \mathrm{C}$ on STO and fused silica substrates) as previously tested to produce the best performance thin films. In both steps, the cooling from deposition temperature to room temperature was accomplished in 300 Torr of oxygen. Gold electrodes were sputtered using a custom Ni mask at room temperature after completion of PLD routes in order to achieve the electrical connection of the p-n couples. The sequence of thin film deposition for on-chip thermoelectric module has been shown in Fig. 1 (a) along with schematic side view of module. The schematic top view of module and a picture of the module surface are shown in Fig. 1(b) and 1(c), respectively.

Due to geometrical constraints in some of the characterization facilities, the $n$-type and $p$-type films were prepared separately on small pieces $(0.4 \times$ $7 \times 0.05 \mathrm{~cm}^{3}$ slabs) of the three kinds of substrates using the same conditions described above. Structural characterization was performed by XRD (Bruker D8 Discover) and morphology was checked by scattering electron microscopy (SEM) (JEOL, FESEM). The thickness and in-plane roughness were obtained by a Keyence VK-9700 3D microscope. The electrical conductivity 
was measured in the temperature range $300 \mathrm{~K}$ to $600 \mathrm{~K}$ by a custom-built four-point-probe technique consisting of a current source (ADCMT 6144), a temperature controller (Cryo-con 32) and a nano voltmeter (Keithley 2182A). Seebeck coefficient was measured in the temperature range $300 \mathrm{~K}$ to $600 \mathrm{~K}$ with a commercially available system (MMR Technologies Inc.).

Performance of modules was evaluated using ad-hoc customized system where the module was set vertically in between alumina (heat source; however heat is generated by hot plate) and aluminum nitride (heat sink) sheet. A schematic of experimental set-up is shown in figure $1(\mathrm{~d})$, where $\mathrm{T}_{h}$ and $\mathrm{T}_{c}$ are hot-end and cold-end temperature of the module, respectively. The generation of thermoelectric voltage was checked by heating the module from the bottom on a hot plate $\left(\mathrm{T}_{h}\right.$ up to $\left.300^{\circ} \mathrm{C}\right)$ while monitoring voltage (by Keithley 2182A) and temperature by means of two K-type thermocouples controlled by TR-KN units (AS-ONE).

This thermoelectric voltage is measured by using a variable resistance (in the range of $10 \mathrm{ohm}$ to $10^{6} \mathrm{ohm}$ ) as external load and power was evaluated at different temperatures. External variable resistance was set for load purpose and the output power was evaluated at different temperatures for each value of external resistance. The maximum output power at each temperature was 
determined as the peak of the polynomial bell-shape fitting the experimental points. A difference of temperature between the two sides of the module was generated by setting a water beaker as a coolant on the top of Aluminum nitride sheet.

\section{Results and Discussion}

AZO thin films served as an $n$-type leg for the on-chip thermoelectric module. We extensively reported about thermoelectric performance of AZO in our previous works $[39,40,44]$. High-quality $c$-axis oriented films were grown on single crystals $\left(\mathrm{Al}_{2} \mathrm{O}_{3}\right.$ and STO) as well as on amorphous fused silica. The optimum conditions of AZO thin films were reported for enhanced thermoelectric performance with respect to the corresponding bulk material. The thermoelectric parameters of AZO thin film on single crystal $\mathrm{Al}_{2} \mathrm{O}_{3}$, STO and amorphous fused silica substrates are summarized in table 1 from our previous reports. The AZO thin film deposited on fused silica substrates shows the best thermoelectric performance in temperature range $300 \mathrm{~K}$ to $600 \mathrm{~K}$.

We further extended our work to prepare a $p$-type leg for on-chip thermoelectric module. For this purpose, we focused on thermoelectric $\mathrm{Ca}_{3} \mathrm{Co}_{4} \mathrm{O}_{9}$ 
thin films on various substrates such as single crystal $\mathrm{Al}_{2} \mathrm{O}_{3}$, STO and amorphous fused silica substrates. The deposition condition were screened and, as main difference respect to AZO, deposition temperature was higher while energy density of the laser beam focused on the target was about a quarter. Thin films of $\mathrm{Ca}_{3} \mathrm{Co}_{4} \mathrm{O}_{9}$ are $c$-axis grown as found in XRD patterns reported in Figure 2. The SEM images of films surface are reported in Fig. 3. All films shows randomly disposed elongated grains with similar dimensions on STO and fused silica while size is bigger on $\mathrm{Al}_{2} \mathrm{O}_{3}$ even if deposition temperature was almost same on the three different substrates.

Within the time-frame of our project, the preliminary thermoelectric parameters for $\mathrm{Ca}_{3} \mathrm{Co}_{4} \mathrm{O}_{9}$ thin films are presented in table 2. The thermoelectric properties of our grown $\mathrm{Ca}_{3} \mathrm{Co}_{4} \mathrm{O}_{9}$ thin films on various substrates are also plotted in Fig. 4. Figure 4(a) shows the electrical conductivity vs temperature $(\sigma-\mathrm{T})$ characteristics of $\mathrm{Ca}_{3} \mathrm{Co}_{4} \mathrm{O}_{9}$ thin films measured by four probes technique. Thin film grown on $\mathrm{Al}_{2} \mathrm{O}_{3}$ substrates shows the best electrical conductivity about $12 \mathrm{~S} / \mathrm{cm}$ at $300 \mathrm{~K}$ and $18 \mathrm{~S} / \mathrm{cm}$ at $600 \mathrm{~K}$. The reason of superior performance of the film grown on $\mathrm{Al}_{2} \mathrm{O}_{3}$ respect to the film on STO may be reached in the lower mismatch: $1.02 \%$ on $\mathrm{Al}_{2} \mathrm{O}_{3}$ and $2.06 \%$ on STO. It is possible to calculate the linear concentration of dislocations gener- 
ated at any film/substrate interface by $\mathrm{L}=\left[\left(\mathrm{a}_{f}-\mathrm{a}_{s}\right) / \mathrm{a}^{2}{ }_{a v g}\right]$, where $\mathrm{a}_{f}, \mathrm{a}_{s}$, and $\mathrm{a}_{\text {avg }}$ are the thin film, substrate, and average lattice parameter, respectively [39]. Assuming a regular distribution, the areal density of dislocations can be calculated as $\mathrm{N}=\mathrm{L}^{2}$. The value of $\mathrm{N}$ varies with substrate and crystalline orientation. In our system, the value of $\mathrm{N}$ is $1.74 \times 10^{11} \mathrm{~cm}^{-2}$ on STO and $2.87 \times 10^{10} \mathrm{~cm}^{-2}$ on $\mathrm{Al}_{2} \mathrm{O}_{3}$. The lower amount of dislocations on $\mathrm{Al}_{2} \mathrm{O}_{3}$ induces a moderate electron scattering, giving higher electrical conductivity. Another factor to be taken into account is the lower amount of scattering at grain boundaries due to the bigger size of the grains in the film grown on $\mathrm{Al}_{2} \mathrm{O}_{3}$. The value of electrical conductivity of our $\mathrm{Ca}_{3} \mathrm{Co}_{4} \mathrm{O}_{9}$ samples is however much lower than our bulk of same composition $(108 \mathrm{~S} / \mathrm{cm}$ at $300 \mathrm{~K}$ and $132 \mathrm{~S} / \mathrm{cm}$ at $600 \mathrm{~K}$ )

The Seebeck coefficient vs temperature $(\mathrm{S}-\mathrm{T})$ characteristics of $\mathrm{Ca}_{3} \mathrm{Co}_{4} \mathrm{O}_{9}$ thin films are measured in temperature range $300 \mathrm{~K}$ to $600 \mathrm{~K}$. The average response for thin film grown on fused silica shows higher value of Seebeck coefficient than the thin films grown on single crystal substrates (STO and $\mathrm{Al}_{2} \mathrm{O}_{3}$ ). The expected trend of substrate dependence of Seebeck coefficient is opposite to electrical conductivity and plotted in Fig. 4(b). The values of Seebeck coefficients are positive which reflects that the thin films are $p$ - 
type thermoelectric. The value of Seebeck coefficients at $300 \mathrm{~K}$ and $600 \mathrm{~K}$ are shown in table 2. The comparison shows that the value of Seebeck coefficient for thin film is higher than the value of our bulk of same composition which is a good indication of the thermoelectric performance of thin film. The best Seebeck coefficients are about $160 \mu \mathrm{V} / \mathrm{K}$ at $300 \mathrm{~K}$ and $186 \mu \mathrm{V} / \mathrm{K}$ at $600 \mathrm{~K}$ for thin films grown on fused silica substrates. Values on both crystalline substrates are closer, and all values are in the same range of typical values reported in literature for thin films or bulk $\mathrm{Ca}_{3} \mathrm{Co}_{4} \mathrm{O}_{9}$.

The performance of thin film is evaluated by the value of power factor (P.F.) which can be calculated by $\sigma . S^{2}$. The value of power factor for $\mathrm{Ca}_{3} \mathrm{Co}_{4} \mathrm{O}_{9}$ thin films are plotted in Fig. 4(c) with the function of temperature. The values of power factor for $300 \mathrm{~K}$ and $600 \mathrm{~K}$ are also summarized in table 2 . The values on thin films are about two orders lower than the value of power factor for our bulk of same composition. This can be solely attributed to the lower electrical conductivity. The best performance is shown by thin films grown on $\mathrm{Al}_{2} \mathrm{O}_{3}$ (0001) single crystal substrates due to higher electrical conductivity and the lower mismatch which helps to enhance the properties. The values of power factor are $0.024 \mathrm{~mW} / \mathrm{m} \cdot \mathrm{K}^{2}$ at $300 \mathrm{~K}$ and $0.045 \mathrm{~mW} / \mathrm{m} . \mathrm{K}^{2}$ at $600 \mathrm{~K}$. The value of power factor can be improved by op- 
timizing the growth condition which includes varying partial oxygen pressure during deposition, deposition temperature and rotation speed of the target. Further we calculated the figure of merit (ZT) of thin films by $\sigma \cdot \mathrm{S}^{2} . \mathrm{T} / \kappa$. We have followed conservative approximation and used two approximations to estimate the value of $\mathrm{ZT}$ of $\mathrm{Ca}_{3} \mathrm{Co}_{4} \mathrm{O}_{9}$ thin films. i) we have used the thermal conductivity of bulk material of same composition at room temperature other than the thermal conductivity of thin films which is not available in literature at the moment. Due to quantum confinement effect the value of thermal conductivity of thin film will be much smaller than the thermal conductivity of bulk material of same composition; ii) the behavior of ZT at elevated temperatures is estimated using thermal conductivity at room temperature $\left(\kappa=\kappa_{300}\right)$ which defines $\mathrm{ZT}$ as $\sigma . \mathrm{S}^{2} . \mathrm{T} / \kappa_{300}$ other than $\sigma . \mathrm{S}^{2} . \mathrm{T} / \kappa$ : since the thermal conductivity of single crystals decreases with increasing temperature due to increased phonon-phonon scattering, we assert this as a conservative approximation [45].

In the case of AZO films, we were able to measure the value of thermal conductivity at room temperature, then we followed the second approximation [45]. The results for $p$-type $\mathrm{Ca}_{3} \mathrm{Co}_{4} \mathrm{O}_{9}$ can be seen in table 2, including the value of thermal conductivity of corresponding bulk, which decreased 
from $2.08 \mathrm{~W} / \mathrm{m} . \mathrm{K}$ (at $300 \mathrm{~K}$ ) to $1.78 \mathrm{~W} / \mathrm{m} . \mathrm{K}$ (at $600 \mathrm{~K}$ ). The figure of merit vs temperature (ZT vs T) characteristics is plotted in Fig. 4(d) and summarized in table 2 . The best performance is shown by thin films deposited on $\mathrm{Al}_{2} \mathrm{O}_{3}$ substrates at $700^{\circ} \mathrm{C}$ which is ZT about 0.004 at $300 \mathrm{~K}$ and 0.013 at 600 K. With reference of our previous reports of AZO thin films, if the thermal conductivity of $\mathrm{Ca}_{3} \mathrm{Co}_{4} \mathrm{O}_{9}$ thin film is an order smaller than the bulk, we will be able to achieve the value of ZT an order higher than the present values and that will be about 0.04 at $300 \mathrm{~K}$ and 0.13 at $600 \mathrm{~K}$. This prediction will result, the value of $\mathrm{ZT}$ for $\mathrm{Ca}_{3} \mathrm{Co}_{4} \mathrm{O}_{9}$ thin film, an order higher than the bulk of same composition.

Combining the conditions of optimized AZO films and preliminary conditions of $\mathrm{Ca}_{3} \mathrm{Co}_{4} \mathrm{O}_{9}$ thin films, we have fabricated the on-chip thermoelectric module on each substrate. We have used 5 legs of each $n$-type and $p$-type thermoelectric thin films on $\mathrm{Al}_{2} \mathrm{O}_{3}$, STO and fused silica substrates, and then we compared the performance of the three modules. The real on-chip thermoelectric module deposited on $\mathrm{Al}_{2} \mathrm{O}_{3}$ is shown in Fig. 1(c). Performance of on-chip thermoelectric module was evaluated using ad-hoc customized system where the module was set vertically for temperature gradient (Fig. 1 (d)). Figure 5(a) shows a schematic of the temperature gradient direction 
and Fig. 5(b) shows the snapshot of the ad-hoc assembly of module mount together with $\mathrm{Al}_{2} \mathrm{O}_{3}$ foam. The power generation characteristics of on-chip thermoelectric module is shown in Fig. 6(a) - 6(c) on various substrates and temperature difference $\left(\Delta \mathrm{T}=\mathrm{T}_{h}-\mathrm{T}_{c}\right)$ of heat source $\left(\mathrm{T}_{h}\right)$ and sink $\left(\mathrm{T}_{c}\right)$. The temperature of heat source varies from $100^{\circ} \mathrm{C}$ to $300^{\circ} \mathrm{C}$ and keeping heat sink temperature near $0^{\circ} \mathrm{C}$. In this range of temperature, the load external resistance was changed from $100 \mathrm{ohm}$ to $1 \mathrm{Mohm}$. The maximum output power $\left(\mathrm{P}_{\max }\right)$ increase with increase in $\Delta \mathrm{T}$ and the highest output power is achieved while keeping higher $\Delta \mathrm{T}$.

For $\mathrm{T}_{h}=300^{\circ} \mathrm{C}$, the summarized plot is presented in Fig. 6(d) for various substrates and overall the best performance of on-chip thermoelectric was obtained on $\mathrm{Al}_{2} \mathrm{O}_{3}$. The value of maximum output power, $\mathrm{P}_{\text {max }}$, of on-chip module is about $0.3 \mathrm{pW}$ on FS, $17.9 \mathrm{pW}$ on $\mathrm{STO}$, and $29.9 \mathrm{pW}$ on $\mathrm{Al}_{2} \mathrm{O}_{3}$ substrates, being at the same level reported by Zappa et. al. on $\mathrm{CuO} / \mathrm{ZnO}$ thin film module [43].

The output power of our thin film module is still far from typical output power of modules based on bulk oxides [9], however this result is encouraging for the practical applications of thermoelectric oxide thin films including the modules on flexible substrates for ubiquitous harvesting of the waste heat. 
The future work will be focused on enhancing the performance of on-chip module which can be done by following steps - i) enhancing thermoelectrical performance of $\mathrm{Ca}_{3} \mathrm{Co}_{4} \mathrm{O}_{9}$ thin film [32]; ii) improving dimensions of $n$-type and $p$-type legs of module [46]; iii) analyzing the material for electrical contact of $n$-type and $p$-type legs of module.

\section{Summary}

The preliminary on-chip thin film thermoelectric module of $n$-type Aldoped $\mathrm{ZnO}$ and $p$-type $\mathrm{Ca}_{3} \mathrm{Co}_{4} \mathrm{O}_{9}$ has been successfully fabricated. The performance of on-chip thermoelectric module is evaluated by ad-hoc customized system where the on-chip module is set vertically. The output power increases with increase in temperature gradient. The best performance is shown by the module which is fabricated on $\mathrm{Al}_{2} \mathrm{O}_{3}$ single crystal substrates. The largest output power was obtained with temperature gradient $\Delta \mathrm{T}=230^{\circ} \mathrm{C}\left(\mathrm{T}_{h}=\right.$ $\left.300^{\circ} \mathrm{C}\right): \mathrm{P}_{\max }=29.9 \mathrm{pW}$ on $\mathrm{Al}_{2} \mathrm{O}_{3}$. The further improvement is possible optimizing the growth condition of $\mathrm{Ca}_{3} \mathrm{Co}_{4} \mathrm{O}_{9}$ thin films in such a way that electrical conductivity should enhance. 
259

260

261

\section{Acknowledgments}

P.M. and S. S. thank Institute for Sustainable Sciences and Development (ISSD), Hiroshima University, Higashi Hiroshima, Japan for partial financial support under the framework of Japan Science and Technology Agency program to Disseminate Tenure Tracking System. P.M. acknowledges partial financial support of Kakenhi (C) grant No. 263901103. S.S. and A.T. want to thank US NSF for support through grant \# 1121252 (MRSEC) and 1407650. P.M. and S.S. thank Prof T. Takabatake and Prof K. Suekuni from Department of Quantum Matter, ADSM, Hiroshima University, Japan for the fruitful discussion and experimental support. We appreciate Prof. P. E. Hopkins, Department of Mechanical and Aerospace Engineering, University of Virginia, USA, for the contribution of thermal conductivity experiment and fruitful discussion. 


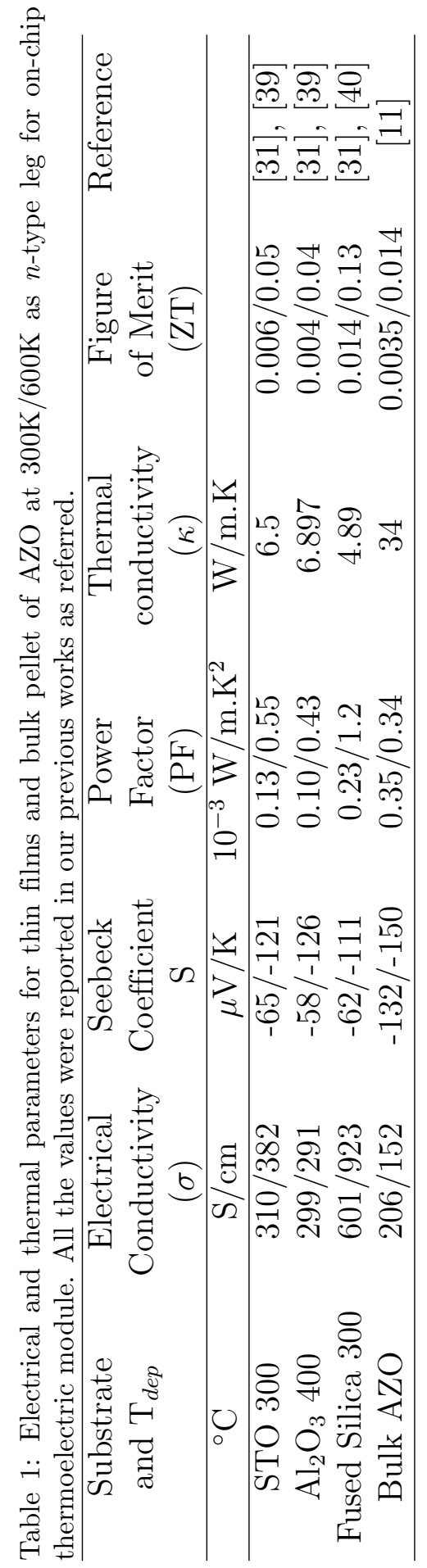




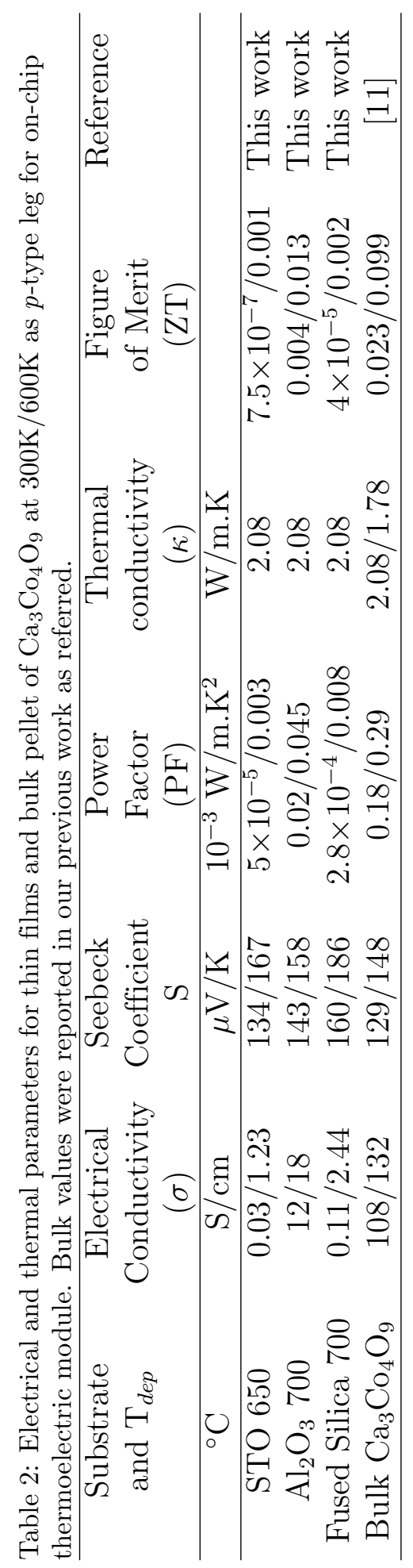




\section{Figure Captions}

Figure 1: (a) 3D sketch of the thin film module with sequence of thin films and electrodes deposition; (b) schematic top view of the module and (c) photograph of the module after fabrication of thin films legs and gold contacts; (d) Schematic of module testing set-up with a load resistor (R).

Figure 2: XRD pattern of $\mathrm{Ca}_{3} \mathrm{Co}_{4} \mathrm{O}_{9}$ thin films deposited on STO, $\mathrm{Al}_{2} \mathrm{O}_{3}$, and fused silica substrates at corresponding deposition temperature.

Figure 3: SEM images of the surface of $\mathrm{Ca}_{3} \mathrm{Co}_{4} \mathrm{O}_{9}$ thin films deposited on (a) STO; (b) $\mathrm{Al}_{2} \mathrm{O}_{3}$; (c) fused silica.

Figure 4: Temperature dependent transport and thermoelectric properties of $\mathrm{Ca}_{3} \mathrm{Co}_{4} \mathrm{O}_{9}$ thin films deposited on several substrates with corresponding deposition temperature $\left(\mathrm{T}_{d e p}\right)$ : (a) electrical conductivity; (b) Seebeck coefficient; (c) Power factor; (d) A dimensional figure of merit.

Figure 5: (a) Flow of heat gradient direction during testing of thermoelectric module; (b) image of thermoelectric module disposed vertically during the power output test.

Figure 6: Output power of thin film thermoelectric modules at increasing temperatures (a) on $\mathrm{Al}_{2} \mathrm{O}_{3}$; (b) on STO and (c) on fused silica; (d) output power of the modules fabricated on the three different substrates at $\mathrm{T}_{h}=$ 
$291300^{\circ} \mathrm{C}$. 


\section{References}

[1] J. W. Fergus, Oxide materials for high temperature thermoelectric energy conversion, Journal of the European Ceramic Society 32 (3) (2012) $525-540$.

[2] M. Ohtaki, Recent aspects of oxide thermoelectric materials for power generation from mid-to-high temperature heat source, Journal of the Ceramic Society of Japan 119 (1395) (2011) 770-775.

[3] N. N. Van, N. Pryds, Nanostructured oxide materials and modules for high-temperature power generation from waste heat, Advances in Natural Sciences: Nanoscience and Nanotechnology 4 (2) (2013) 023002.

[4] J. He, Y. Liu, R. Funahashi, Oxide thermoelectrics: the challenges, progress, and outlook, Journal of Materials Research 26 (15) (2011) $1762-1772$.

[5] K. Koumoto, R. Funahashi, E. Guilmeau, Y. Miyazaki, A. Weidenkaff, Y. Wang, C. Wan, Thermoelectric ceramics for energy harvesting, Journal of the American Ceramic Society 96 (1) (2013) 1-23.

[6] L. T. Hung, N. Van Nong, G. J. Snyder, M. H. Viet, B. Balke, L. Han, 
E. Stamate, S. Linderoth, N. Pryds, High performance p-type segmented leg of misfit-layered cobaltite and half-heusler alloy, Energy Conversion and Management 99 (2015) 20-27.

[7] L.-D. Zhao, S.-H. Lo, Y. Zhang, H. Sun, G. Tan, C. Uher, C. Wolverton, V. P. Dravid, M. G. Kanatzidis, Ultralow thermal conductivity and high thermoelectric figure of merit in SnSe crystals, Nature 508 (7496) (2014) $373-377$.

[8] M. Ohtaki, K. Araki, K. Yamamoto, High thermoelectric performance of dually doped $\mathrm{ZnO}$ ceramics, Journal of Electronic Materials 38 (7) (2009) 1234-1238.

[9] N. Van Nong, N. Pryds, S. Linderoth, M. Ohtaki, Enhancement of the thermoelectric performance of p-type layered oxide $\mathrm{Ca}_{3} \mathrm{Co}_{4} \mathrm{O}_{9+\delta}$ through heavy doping and metallic nanoinclusions, Advanced Materials 23 (21) (2011) 2484-2490.

[10] S.-M. Choi, K.-H. Lee, C.-H. Lim, W.-S. Seo, Oxide-based thermoelectric power generation module using p-type $\mathrm{Ca}_{3} \mathrm{Co}_{4} \mathrm{O}_{9}$ and n-type (Zno) ${ }_{7} \mathrm{In}_{2} \mathrm{O}_{3}$ legs, Energy Conversion and Management 52 (1) (2011) $335-339$. 
[11] P. Mele, H. Kamei, H. Yasumune, K. Matsumoto, K. Miyazaki, Development of thermoelectric module based on dense $\mathrm{Ca}_{3} \mathrm{Co}_{4} \mathrm{O}_{9}$ and $\mathrm{Zn}_{0.98} \mathrm{Al}_{0.02} \mathrm{O}$ legs, Metals and Materials International 20 (2) (2014) 389397.

[12] L. Hicks, M. Dresselhaus, Thermoelectric figure of merit of a onedimensional conductor, Physical review B 47 (24) (1993) 16631.

[13] L. Hicks, M. Dresselhaus, Effect of quantum-well structures on the thermoelectric figure of merit, Physical Review B 47 (19) (1993) 12727.

[14] W. Liu, X. Yan, G. Chen, Z. Ren, Recent advances in thermoelectric nanocomposites, Nano Energy 1 (1) (2012) 42-56.

[15] M. Martín-González, O. Caballero-Calero, P. Díaz-Chao, Nanoengineering thermoelectrics for $21^{\text {st }}$ century: Energy harvesting and other trends in the field, Renewable and Sustainable Energy Reviews 24 (2013) 288305.

[16] C. J. Vineis, A. Shakouri, A. Majumdar, M. G. Kanatzidis, Nanostructured thermoelectrics: big efficiency gains from small features, Advanced Materials 22 (36) (2010) 3970-3980. 
[17] A. Shakouri, Recent developments in semiconductor thermoelectric physics and materials, Materials Research 41 (1) (2011) 399.

[18] N. Wang, H. Chen, H. He, W. Norimatsu, M. Kusunoki, K. Koumoto, Enhanced thermoelectric performance of Nb-doped $\mathrm{SrTiO}_{3}$ by nanoinclusion with low thermal conductivity, Scientific reports 3.

[19] R. Venkatasubramanian, E. Siivola, T. Colpitts, B. O'Quinn, Thin-film thermoelectric devices with high room-temperature figures of merit, Nature 413 (6856) (2001) 597-602.

[20] M. G. Kanatzidis, Nanostructured thermoelectrics: The new paradigm?† ${ }^{\dagger}$ Chemistry of Materials 22 (3) (2009) 648-659.

[21] M. Ohtaki, K. Araki, Thermoelectric properties and thermopower enhancement of $\mathrm{Al}$-doped $\mathrm{ZnO}$ with nanosized pore structure, Journal of the Ceramic Society of Japan 119 (1395) (2011) 813-816.

[22] G. Kim, L. Shao, K. Zhang, K. P. Pipe, Engineered doping of organic semiconductors for enhanced thermoelectric efficiency, Nature Materials $12(8)(2013)$ 719-723.

[23] H. Alam, S. Ramakrishna, A review on the enhancement of figure of 
merit from bulk to nano-thermoelectric materials, Nano Energy 2 (2) (2013) 190-212.

[24] K.-H. Jung, K. H. Lee, W.-S. Seo, S.-M. Choi, An enhancement of a thermoelectric power factor in a Ga-doped $\mathrm{ZnO}$ system: A chemical compression by enlarged Ga solubility, Applied Physics Letters 100 (25) (2012) 253902.

[25] S. Butt, Y. Ren, M. U. Farooq, B. Zhan, R. U. R. Sagar, Y. Lin, C.-W. Nan, Enhanced thermoelectric performance of heavy-metals (M: Ba, $\mathrm{Pb})$ doped misfit-layered ceramics: $\left(\mathrm{Ca}_{2-x} M_{x} \mathrm{coO}_{3}\right)_{0.62}\left(\mathrm{CoO}_{2}\right)$, Energy Conversion and Management 83 (2014) 35-41.

[26] R. Ramesh, N. A. Spaldin, Multiferroics: progress and prospects in thin films, Nature materials 6 (1) (2007) 21-29.

[27] D. G. Schlom, L.-Q. Chen, C. J. Fennie, V. Gopalan, D. A. Muller, X. Pan, R. Ramesh, R. Uecker, Elastic strain engineering of ferroic oxides, Mrs Bulletin 39 (02) (2014) 118-130.

[28] K. Matsumoto, P. Mele, Artificial pinning center technology to enhance vortex pinning in YBCO coated conductors, Superconductor Science and Technology 23 (1) (2010) 014001. 
[29] G. Fu, G. Yan, L. Sun, H. Zhang, H. Guo, J. Wang, S. Wang, Enhanced transparent conducting performance of c-axis oriented $\mathrm{Ca}_{3} \mathrm{Co}_{4} \mathrm{O}_{9}$ thin films, RSC Advances 5 (33) (2015) 26383-26387.

[30] S. Y. Park, B. J. Kim, K. Kim, M. S. Kang, K.-H. Lim, T. I. Lee, J. M. Myoung, H. K. Baik, J. H. Cho, Y. S. Kim, Low-temperature, solutionprocessed and alkali metal doped $\mathrm{ZnO}$ for high-performance thin-film transistors, Advanced Materials 24 (6) (2012) 834-838.

[31] P. Mele, Nanostructured thin films of thermoelectric oxides, in: Oxide Thin Films, Multilayers, and Nanocomposites, Springer, 2015, pp. 123155.

[32] T. Sun, H. Hng, Q. Yan, J. Ma, Enhanced high temperature thermoelectric properties of Bi-doped c-axis oriented $\mathrm{Ca}_{3} \mathrm{Co}_{4} \mathrm{O}_{9}$ thin films by pulsed laser deposition., JOURNAL OF APPLIED PHYSICS 108 (2010) 083709.

[33] P. Jood, G. Peleckis, X. Wang, S. X. Dou, Thermoelectric properties of $\mathrm{Ca}_{3} \mathrm{Co}_{4} \mathrm{O}_{9}$ and $\mathrm{ca}_{2.8} \mathrm{bi}_{0.2} \mathrm{CO}_{4} \mathrm{O}_{9}$ thin films in their island formation mode, JOURNAL OF APPLIED PHYSICS 28 (14) (2013) 1932-1939.

[34] R. Wei, H. Jian, X. Tang, J. Yang, L. Hu, L. Chen, J. Dai, X. Zhu, 
Y. Sun, Enhanced thermoelectric properties in Cu-doped c-axis-oriented $\mathrm{Ca}_{3} \mathrm{Co}_{4} \mathrm{O}_{9+\delta}$ thin films, Journal of the American Ceramic Society 96 (8) (2013) 2396-2401.

[35] A. Abutaha, S. S. Kumar, H. N. Alshareef, Crystal orientation dependent thermoelectric properties of highly oriented aluminum-doped zinc oxide thin films, Applied Physics Letters 102 (5) (2013) 053507.

[36] N. Vogel-Schäuble, Y. E. Romanyuk, S. Yoon, K. J. Saji, S. Populoh, S. Pokrant, M. H. Aguirre, A. Weidenkaff, Thermoelectric properties of nanostructured Al-substituted ZnO thin films, Thin Solid Films 520 (23) (2012) 6869-6875.

[37] J. Loureiro, N. Neves, R. Barros, T. Mateus, R. Santos, S. Filonovich, S. Reparaz, C. M. Sotomayor-Torres, F. Wyczisk, L. Divay, et al., Transparent aluminium zinc oxide thin films with enhanced thermoelectric properties, Journal of Materials Chemistry A 2 (18) (2014) 6649-6655.

[38] H. Ohta, Thermoelectrics based on strontium titanate, Materials Today $10(10)(2007) 44-49$.

[39] P. Mele, S. Saini, H. Honda, K. Matsumoto, K. Miyazaki, H. Hagino, 
A. Ichinose, Effect of substrate on thermoelectric properties of Al-doped ZnO thin films, Applied Physics Letters 102 (25) (2013) 253903.

[40] S. Saini, P. Mele, H. Honda, D. J. Henry, P. E. Hopkins, L. Molina-Luna, K. Matsumoto, K. Miyazaki, A. Ichinose, Enhanced thermoelectric performance of $\mathrm{Al}$-doped $\mathrm{ZnO}$ thin films on amorphous substrate, Japanese Journal of Applied Physics 53 (6) (2014) 060306.

[41] W. Somkhunthot, N. Pimpabute, A. Vora-Ud, T. Seetawan, T. Burinprakhon, Thermoelectricity of p-NCO and n-ZAO thin films, in: Advanced Materials Research, Vol. 931, 2014, pp. 386-391.

[42] P. Markowski, M. Presečnik, M. Košir, A. Dziedzic, S. Bernik, et al., Development of thick-film thermoelectric microgenerators based on ptype $\mathrm{Ca}_{3} \mathrm{Co}_{4} \mathrm{O}_{9}$ and n-type $(\mathrm{ZnO})_{5} \mathrm{In}_{2} \mathrm{O}_{3}$ legs, Ceramics International 41 (10) (2015) 13201-13209.

[43] D. Zappa, S. Dalola, G. Faglia, E. Comini, M. Ferroni, C. Soldano, V. Ferrari, G. Sberveglieri, Integration of $\mathrm{ZnO}$ and $\mathrm{CuO}$ nanowires into a thermoelectric module, Beilstein journal of nanotechnology 5 (1) (2014) $927-936$.

[44] S. Saini, P. Mele, H. Honda, K. Matsumoto, K. Miyazaki, L. M. Luna, 
P. Hopkins, Influence of postdeposition cooling atmosphere on thermoelectric properties of $2 \% \mathrm{Al}$-doped $\mathrm{ZnO}$ thin films grown by pulsed laser deposition, Journal of Electronic Materials 44 (6) (2015) 1547-1553.

[45] G. Nolas, H. Goldsmid, Thermal conductivity of semiconductors, in: Thermal Conductivity, Springer, 2004, pp. 105-121.

[46] D. Rowe, G. Min, Design theory of thermoelectric modules for electrical power generation, IEEE Proceedings-Science, Measurement and Technology 143 (6) (1996) 351-356. 
Step 4: Electrodes

(a)

Step 3: AZO thin film

Step 2: $\mathrm{Ca}_{3} \mathrm{Co}_{4} \mathrm{O}_{9}$ thin film

Step 1: Substrate

\section{Side View}

(b)
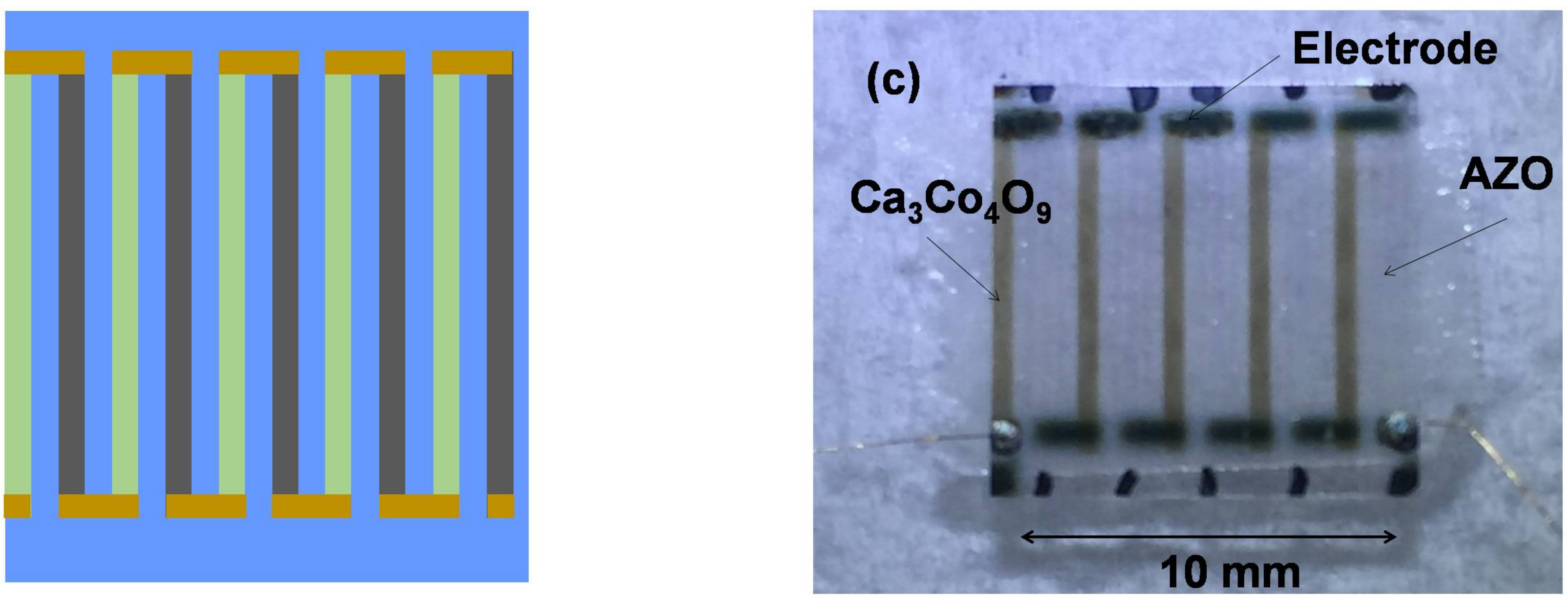

Top View

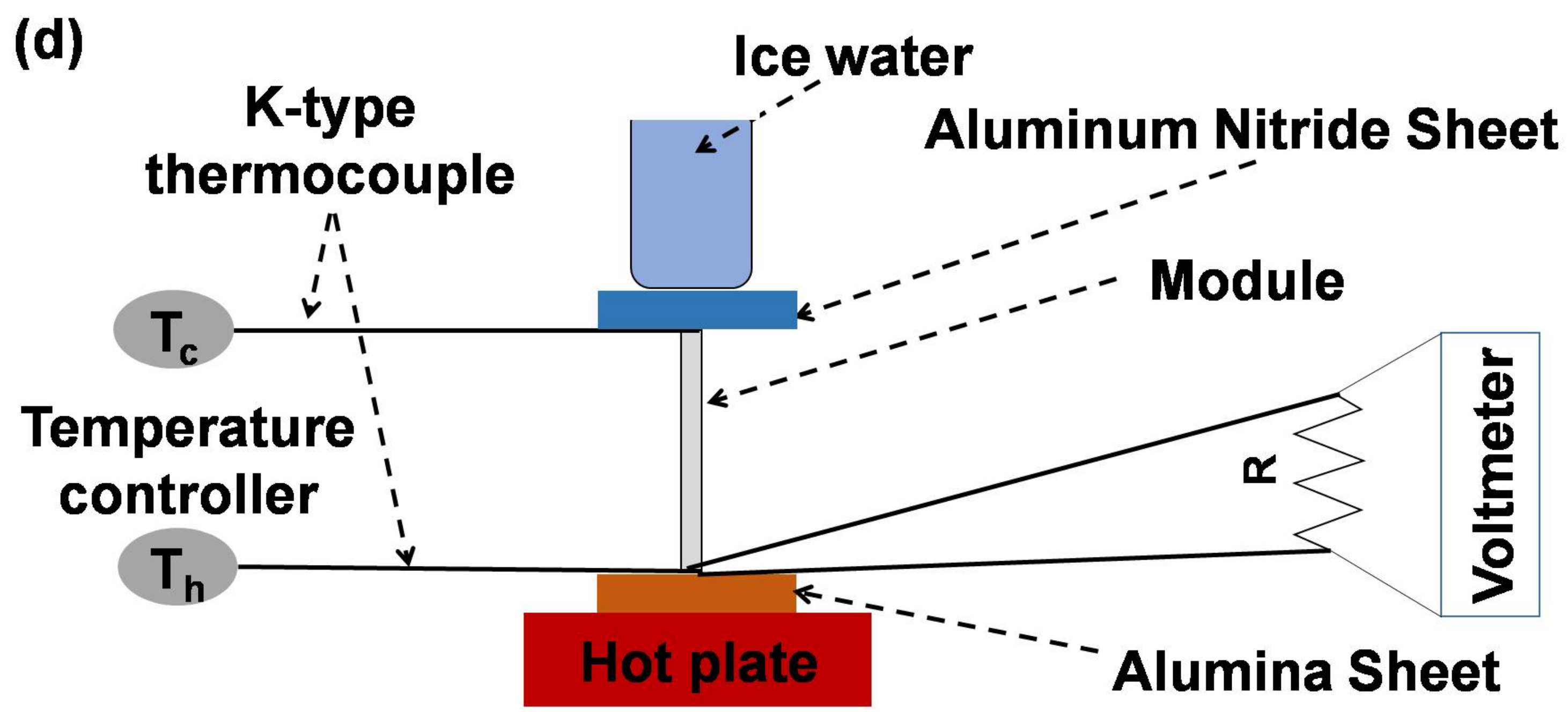


Figure 2

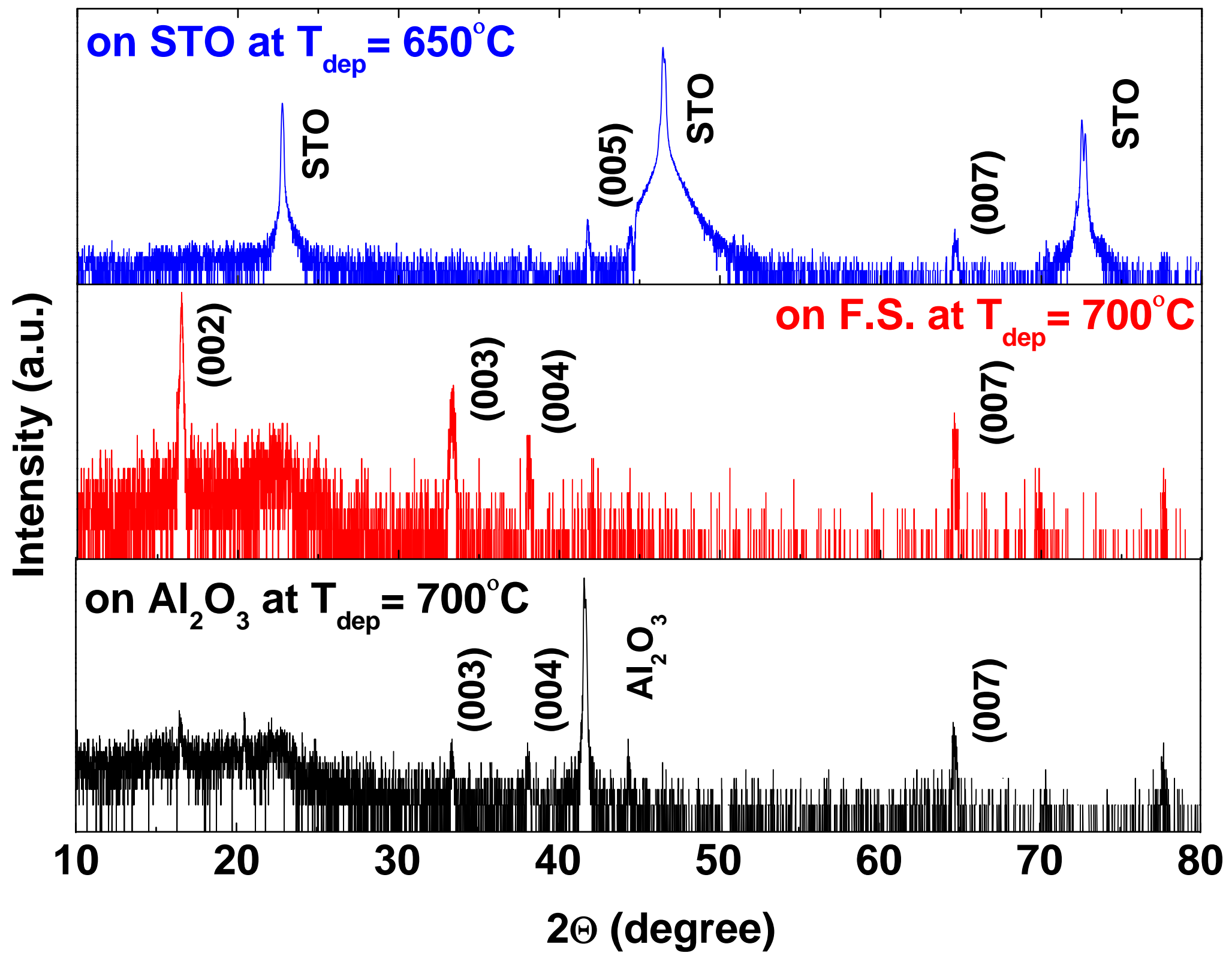


Figure 5

(a)

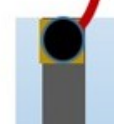

(b) $\mathrm{Al}_{2} \mathrm{O}_{3}$ foam

\section{Module}

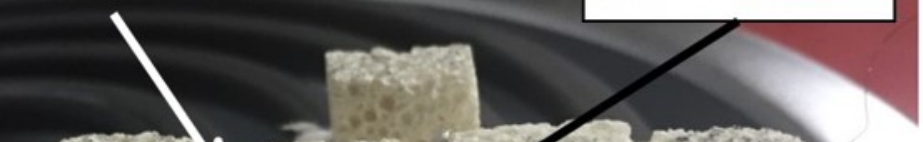

2
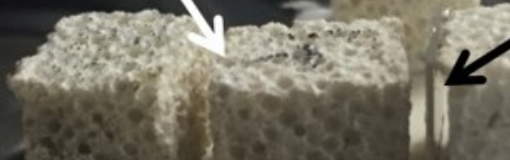

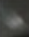

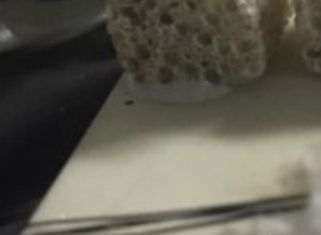


(a) On-chip thermoelectric module on $\mathrm{Al}_{2} \mathrm{O}_{3}$ substrates

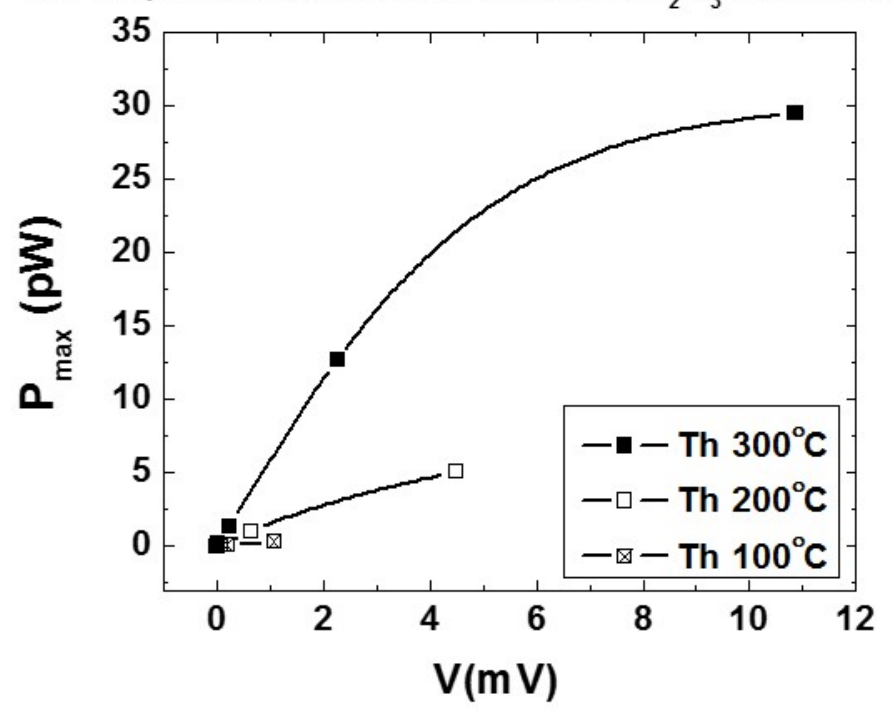

(c) On-chip thermoelectric module on STO substrates

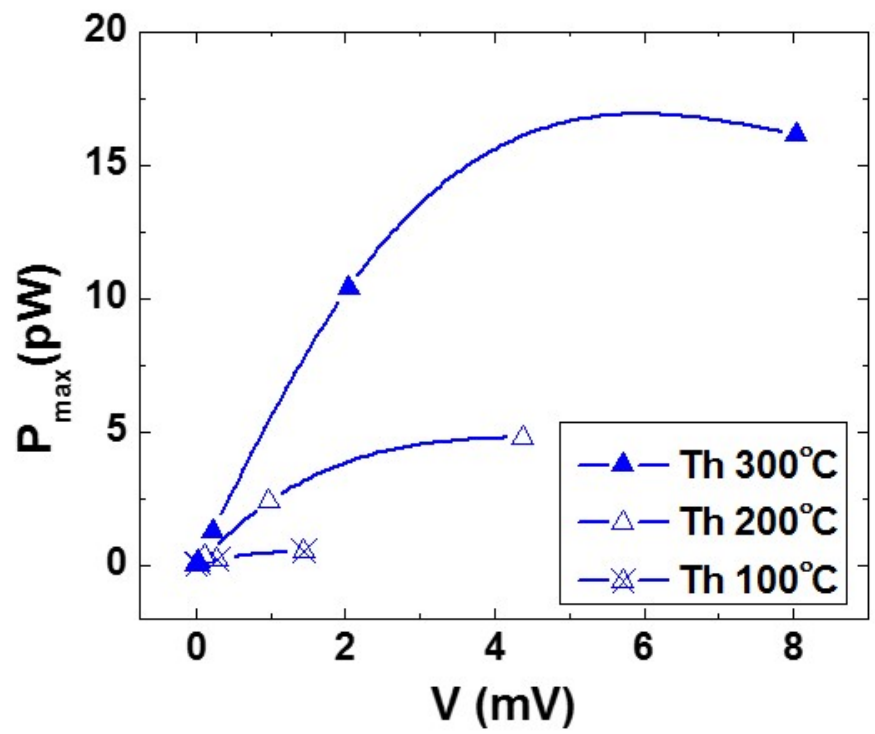

(b) On-chip thermoelectric module on F.S. substrates

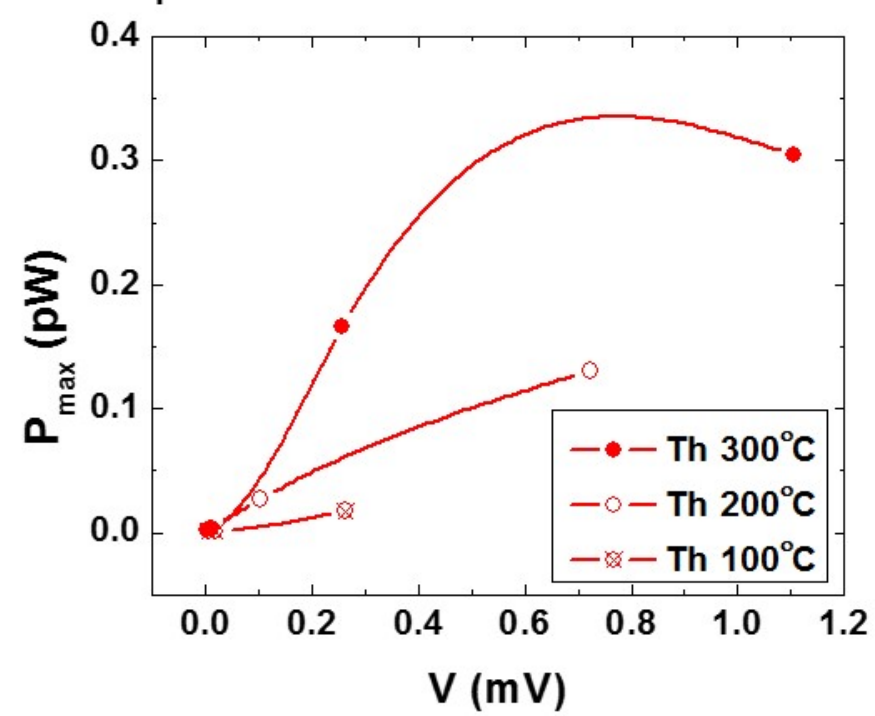

(d)

On-chip thermoelectric module ( Th $300^{\circ} \mathrm{C}$ )

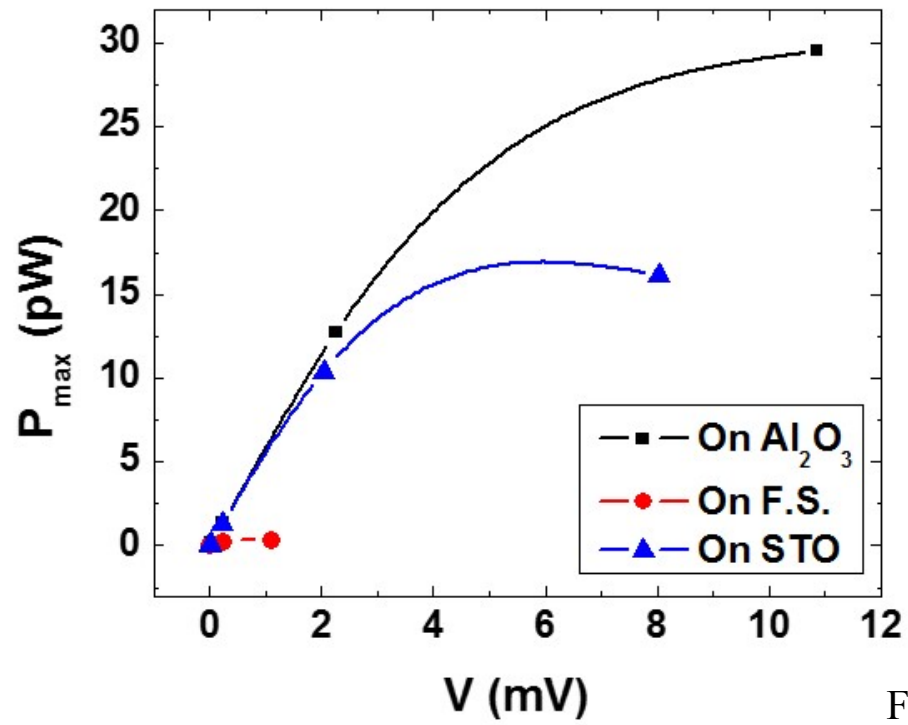

